\title{
Multi-annual variations in winter westerly disturbance activity affecting the Himalaya
}

\author{
Forest Cannon - Leila M. V. Carvalho - Charles Jones • \\ Bodo Bookhagen
}

Received: 11 July 2013 / Accepted: 2 July 2014

(C) Springer-Verlag Berlin Heidelberg 2014

\begin{abstract}
Winter westerly disturbances (WWD) are the primary climatic influence within High Mountain Asia during the boreal winter. Here we investigate variations and changes in WWD over the period 1979-2010 and relationships with heavy (85th percentile) precipitation in the Karakoram/western Himalaya $(\mathrm{KH})$ and central Himalaya $(\mathrm{CH})$ using multiple datasets. We show that heavy precipitation events occurring in the $\mathrm{KH}$ and $\mathrm{CH}$ are often spatiotemporally independent, suggesting differing behavior of WWD affecting each region. The wavelet power spectrum of $200 \mathrm{hPa}$ geopotential height anomalies is used to characterize the frequency and magnitude of individual disturbances and to distinguish synoptic scale variability through time. Our analysis exhibits an enhancement in the strength and frequency of WWD in the $\mathrm{KH}$ and indicates an increase in local heavy precipitation events. In contrast, the $\mathrm{CH}$ is observed to experience weakening influence of these disturbances and consequently, a decrease in heavy precipitation. Furthermore, we investigate multi-annual variability of WWD and teleconnections with some known modes of climate variability affecting central Asia, including the Arctic Oscillation, Eurasian/Polar Pattern, the El Niño Southern Oscillation, and the Siberian High. Although there is clear evidence that these modes affect circulation and precipitation in High Mountain Asia, their competing influences on WWD are complex and non-linear. These results suggest that a thorough understanding of WWD and their
\end{abstract}

F. Cannon $(\bowtie) \cdot$ L. M. V. Carvalho $\cdot$ C. Jones $\cdot$ B. Bookhagen Department of Geography, University of California, Santa Barbara, Santa Barbara, CA 93106, USA e-mail: fcannon@geog.ucsb.edu

L. M. V. Carvalho $\cdot$ C. Jones $\cdot$ B. Bookhagen

Earth Research Institute, University of California, Santa Barbara, Santa Barbara, CA, USA spatiotemporal variations are crucial to improve our knowledge of the hydrologic cycle within High Mountain Asia as well as our ability to project the future status of Asia's water resources.

Keywords Winter westerly disturbances - Karakoram · Himalaya $\cdot$ Heavy precipitation $\cdot$ Teleconnections

\section{Introduction}

The future state of high-elevation freshwater reservoirs in High Mountain Asia is of critical importance to the security of water for consumption, agriculture, and power generation throughout densely populated regions of south, east, and central Asia (Kaab et al. 2012). Variations and changes in the hydrological cycle result from complex human and environmental relationships that are largely dictated by climatic phenomena on a broad range of spatiotemporal scales. Glacier records in the eastern and central Himalaya $(\mathrm{CH})$ yield some of the world's most rapid retreat rates (Scherler et al. 2011). However, there are a number of steady state or positive mass-balance glaciers in the Karakoram and western Himalaya $(\mathrm{KH})$ regions (Bookhagen and Burbank 2010; Kaab et al. 2012; Bolch et al. 2012; Gardelle et al. 2012). In short, dominant climatic controls on the region's glacial mass-balance are not well understood.

The regional climate of the Greater Himalaya is influenced by two predominant systems: The Indian Summer Monsoon (ISM) that extends approximately from June to September and winter westerly disturbances (WWD) from December to March. The interplay between these systems results in two distinct climatic regimes with differing precipitation and water storage characteristics (Bookhagen 
and Burbank 2010). There is an east-west gradient in monsoonal influence across the Himalaya with the $\mathrm{CH}$ receiving up to $80 \%$ of its annual precipitation during the monsoon months. In contrast, the $\mathrm{KH}$ receives more than $50 \%$ of its precipitation during the winter months from WWD (Lang and Barros 2004).

Strong terrain-locked negative anomalies generated by WWD in the 200 and $500 \mathrm{hPa}$ geopotential height fields at the synoptic scale are associated with significant snowstorms in the Himalaya (Lang and Barros 2004). These systems are characterized by the propagation of troughs and ridges in a wavelike pattern that disturbs the upper level jet and produces changes in atmospheric dynamic and thermodynamic characteristics throughout the troposphere resulting in anomalous precipitation, moisture, temperature and circulation. Propagating WWD are strongly related to the development of extra-tropical cyclones and associated frontal systems that affect the weather in the $\mathrm{KH}$ and adjacent regions during winter and spring (Ridley et al. 2013).

Precipitation produced by WWD is supplied by advected moisture from the Mediterranean, Caspian and Arabian seas (Singh et al. 1995; Barlow et al. 2005). The KH orography induces a significant blocking effect (Froude number less than unity; Galewsky 2009) thereby modifying the regional and large-scale circulation and producing significant orographic precipitation. Furthermore, the blocking of flows associated with these events exhibits complex channelization. Numerical simulation in Barros et al. (2006) indicated that river valleys serve as open conduits for moisture into the lee of the incident topography during depressions affecting the $\mathrm{CH}$. Lang and Barros (2004) investigated atmospheric depression's effects on snowfall totals in the $\mathrm{CH}$. Their research found an unambiguous connection between the occurrence of snowfall events and negative geopotential height anomalies over the KH. Snowfall is a primary determinant of glacial mass-balance in High Mountain Asia (Bolch et al. 2012) and consequently is important to regional water resources.

Evidence of trends in glacier records in the $\mathrm{KH}$ has motivated recent studies on wintertime climate variation and change in this region (Archer and Fowler 2004; Bhutiyani et al. 2010; Dimri and Dash 2012; Palazzi et al. 2013). Dimri and Dash (2012) investigated trends in temperature and precipitation using historical wintertime measurements (1975-1976 to 2006-2007). Their results indicated that most of the $\mathrm{KH}$ shows significant increasing trends in the lower and higher percentile of the daily maximum, minimum and average temperatures, and more warm events compared to fewer cold events. In contrast, they observed a general decreasing trend in precipitation in most stations, but these trends were not spatially coherent. Similar station data analysis in the upper Indus Basin (Archer and Fowler 2004) indicated similar temperature trends, but significant increases in winter precipitation from 1961-1999. Furthermore, Palazzi et al. (2013) illustrated numerous complexities in discerning precipitation trends within the HinduKush Karakoram in recent decades using satellite rainfall estimates, reanalyses, and gridded in situ rain gauge data as well as in future climate scenarios using the global climate model EC-Earth. Because temperature and precipitation exhibit a high degree of spatial heterogeneity, there remain significant questions regarding the influence of lower tropospheric warming on WWD activity, and consequently, the regional hydrological cycle.

Linkages between the regional hydrological cycle and global atmospheric variability further complicate this question. Atmospheric modes such as the Arctic Oscillation (AO), Siberian High (SH), Polar/Eurasian Pattern (PE) and the El Niño-Southern Oscillation (ENSO) play an important role in the interannual climatic variability of the $\mathrm{KH}$ by modulating the strength or position of the Asian jet (Barlow et al. 2005; Syed et al. 2006; Yadav et al. 2010). The position of mid- and upper-tropospheric troughs in the zonal westerlies influences the strength and vertical extent of WWD (Ridley et al. 2013). The AO, associated with pressure anomalies in mid-latitudes and polar regions, describes the North-South vacillations in the extratropical zonal wind (Thompson and Wallace 1998). The AO is dynamically associated with the PE, which reflects major changes in the strength of circumpolar circulation. Lang and Barros (2004) found the PE to significantly influence geopotential height in the WWD track affecting $\mathrm{CH}$. The AO, PE and ENSO have previously been linked to modifications of the wintertime westerly jet as well as precipitation totals over the KH (Syed et al. 2006; Yadav et al. 2010). Yadav et al. (2010) found a statistically significant correlation between the Niño 3.4 index and northwest India precipitation for the period 1968-2008, with an increasingly strong correlation for the period 1979-2008. In this work, we also consider the $\mathrm{SH}$, which is a predominant thermal high positioned over northern continental Asia. This mode alters WWD storm tracks by spreading cold, dry, continental air outward, in association with location changes of the subtropical jet (Cohen et al. 2001). The strength of the high can determine the angle of WWD approach to the Himalaya as well as its continued propagation.

The primary modes of variability influencing northern hemisphere climate are not independent. The AO, SH, and PE exhibit documented feedbacks between each mode that greatly complicate large-scale circulation (Cohen et al. 2007). Furthermore, High Mountain Asia lies in a unique region where climate is influenced by complex interactions with these modes (Bothe et al. 2012). Cohen et al. (2007) attributed much of wintertime variability in northern hemisphere climate to the rapid spread of snow cover over Eurasia during the boreal fall. Abrupt increases in snow cover 
raise albedo thus quickly reducing diabatic heating in the lower troposphere. This initiates subsidence and produces an increasingly large mass of cold, dense air. The intensified thermal surface high, known as the $\mathrm{SH}$, decreases energy transport into the stratosphere and reduces the meridional temperature gradient, thus decreasing the PE and AO. Negative phases of these two modes weaken the upper-level zonal wind and reduce dynamic instability aloft, thus further enhancing subsidence over Eurasia in a positive feedback during winter months (Gong et al. 2001; Wu and Wang 2002a, b; Takaya and Nakamura 2005). The noted feedbacks and associated lags illuminate difficulties in attributing a climate signal in High Mountain Asia to any one mode. Bothe et al. (2012) investigated relations between High Mountain Asia precipitation and large-scale climate indices during the summer season. Their findings noted that covariability between High Mountain Asia summer precipitation and atmospheric modes (including ENSO and the AO) changed over recent decades, further complicating regional dynamics. Additionally, linkages in large-scale circulation between seasons are an important consideration in fully understanding the effects of atmospheric modes on High Mountain Asia, which are not discussed here (Bothe et al. 2012).

Recognizing the dynamic relationship between WWD and primary modes of variability is necessary to understand and predict the future climatic conditions of High Mountain Asia. Ridley et al. (2013) examined regional modeling projections and concluded that WWD activity will increase through the 21st century, producing increased winter precipitation for the $\mathrm{KH}$. However, studies regarding the prognosis of WWD activity and Greater Himalaya winter precipitation using global and regional climate models must accurately represent the known modes of atmospheric variability to effectively project the future status of WWD (Syed et al. 2010).

This study has two main objectives. Primarily, we use satellite precipitation estimates, rain-gauge data, and reanalysis data to examine variations and changes in the synoptic activity affecting High Mountain Asia in recent decades (1979-2010). The focus of this analysis is on heavy (85th percentile) precipitation events associated with the propagation of synoptic systems from midlatitudes toward the Himalaya. In this context, we investigate the differences between the $\mathrm{KH}$ and $\mathrm{CH}$ and their respective multiannual variations in synoptic activity. Secondly, we investigate variability in the $\mathrm{AO}, \mathrm{SH}, \mathrm{PE}$ and ENSO and explore how the joint behavior of these modes may have influenced the observed synoptic activity within the greater Himalaya.

\section{Data}

Meteorological data in the topographically heterogeneous Himalaya is limited. Within the Karakoram study region, the observation network thins considerably due to the increased elevation and remoteness of the range. Furthermore, extant data is generally of poor quality due to sampling errors or biases. This research utilizes remotely sensed satellite precipitation estimates and reanalysis data to supplement in situ measurements. It is important to note that both in situ station data and satellite precipitation estimates have difficulty detecting the snow component of precipitation (Rasmussen et al. 2012).

Heavy (85th percentile) precipitation events are investigated using tropical rainfall measurement mission 3B42V6 (TRMM) and Asian precipitation highly resolved observational data integration towards evaluation (APHRODITE). TRMM provides near-global $0.25^{\circ}$ resolution precipitation estimates at 3-h intervals for the period 1998-2013 (Huffman et al. 2007; Bookhagen 2010). It is a multisatellite precipitation analysis data set that combines TRMM 2B31 and TRMM 2A12 data products, Special Sensor Microwave Imager, Advanced Microwave Scanning Radiometer, Advanced Microwave Sounding Units and Climate Prediction Center Infrared observations to estimate precipitation over low/mid-latitudes. TRMM has well known deficiencies in estimating light precipitation as well as solid-state precipitation (TRMM Working Group Summaries 2003; Lang and Barros 2004; Barros et al. 2006). This inability to measure snowfall is particularly problematic for our study given that we are investigating high elevations during winter. In this work, the focus is placed on the timing of precipitation rather than quantity. We assume that low elevation rainfall recorded in a $0.25^{\circ}$ cell is simultaneously producing high elevation snowfall within that cell. Though our quantitative estimates of total precipitation are not realistic, the timing of the heavy events relative to the rest of events within our study region does not change. Barros et al. (2000) demonstrated that TRMM PR estimates of low elevation precipitation in the $\mathrm{CH}$ compared well with station observations.

TRMM's relatively short 16-year precipitation record is not adequate for analyzing long-term variability and is thus supplemented by APHRODITE at daily $0.25^{\circ}$ resolution 1951-2007 (Yatagai et al. 2009) for analysis spanning 1979-2007. APHRODITE data are produced using distance-weighted interpolation between station observations, which performs less than ideally over the Himalaya where observations are sparse and topography is complex. Also, the APHRODITE product used (1003R1) does not discriminate snow from total precipitation. Correlations between TRMM and APHRODITE daily and monthly mean precipitation during the winter (DJFM) 1998-2007 are shown in Fig. 1. At daily temporal resolution, the two products are well correlated over the central Himalaya during the winter months (Pearson correlation coefficient greater than 0.6 for the central Himalaya and greater than 0.35 for the 
Karakoram, Fig. 1). We note the chance of similar stations being used for interpolating APHRODITE and biascorrecting TRMM, which may contribute to the observed correlation.

Daily Climate Forecast System Reanalysis (CFSR) (Saha et al. 2010) from the National Center for Environmental Prediction at $0.5^{\circ}$ grid spacing for the time period 1979-2010 are used to examine $200 \mathrm{hPa}$ geopotential height (H200), $200 \mathrm{hPa}$ zonal wind, mean sea-level pressure and vertically integrated meridional moisture flux affecting the Himalaya at regional and continental scales. CFSR was chosen on account of its model coupling, spatial resolution, and modern assimilation system (Saha et al.

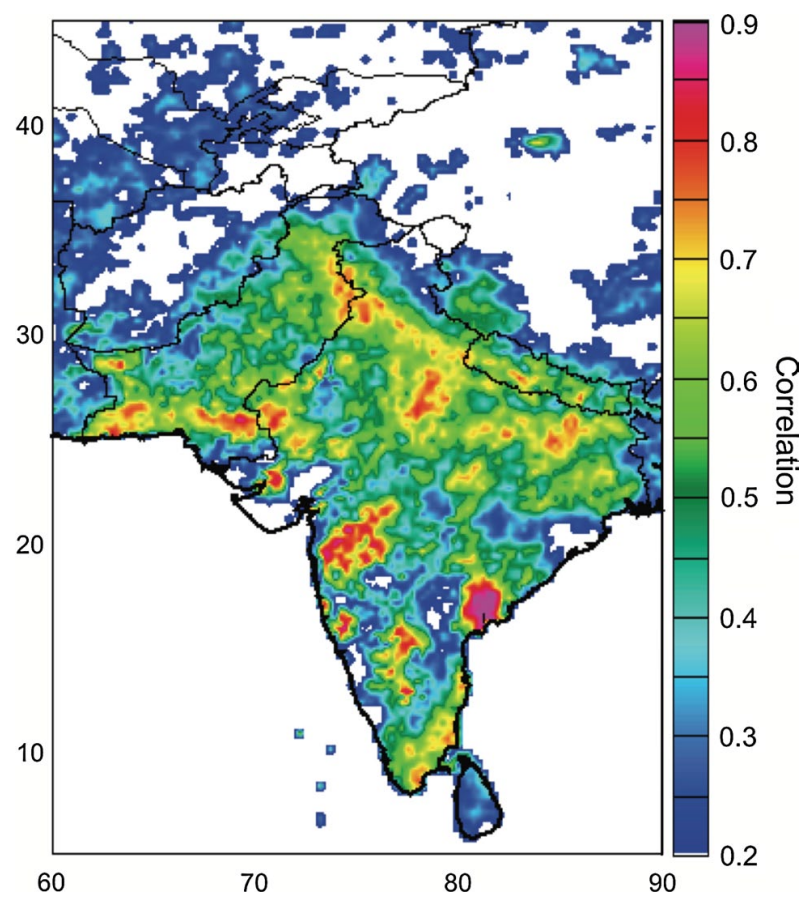

Fig. 1 TRMM-3B42 and AHRODITE (DJFM) daily precipitation correlation 1998-2007
2010). CFSR's horizontal resolution is the best available for resolving the study region's complex topography.

The AO, PE, and ENSO indices used for this study were procured from the National Weather Service Climate Prediction Center (www.cpc.ncep.noaa.gov). The SH index was created by spatially averaging sea-level pressure over the region $80-120^{\circ} \mathrm{E}, 40-65^{\circ} \mathrm{N}$ (Panagiotopoulos et al. 2005).

\section{Heavy precipitation events}

The Himalaya is an expansive mountain range with varying climatology across the region. For the wintertime $\mathrm{KH}$, heavy precipitation events produced by WWD are a primary influence on regional glacial mass-balance (Bolch et al. 2012). This study focuses on two regions: The KH, where glacial mass-balance has increased, and the $\mathrm{CH}$, where negative trends have been documented previously (Bookhagen and Burbank 2010; Bolch et al. 2012). Heavy precipitation events were selected using TRMM and APHRODITE daily precipitation data $\left(0.25^{\circ}\right.$ resolution) over the region of interest. For the $\mathrm{KH}$, the region $74-77^{\circ} \mathrm{E}$, $34-37^{\circ} \mathrm{N}$ was selected to correspond to the extent of the Karakoram (Fig. 2 left). The $\mathrm{CH}$ is oriented NW to SE and thus a diagonal grid is used to minimize the number of low-elevation gridpoints used in our precipitation analysis. Gridpoints covering the greater Himalaya from $84-88 \mathrm{E}$ (ranging from $28-29 \mathrm{~N}$ at $84 \mathrm{E}$ to $27.5-28 \mathrm{~N}$ at $88 \mathrm{E}$ ) were selected (Fig. 2 left) and include high elevations from Annapurna to Kangchenjunga, east of Everest. Daily precipitation estimates were spatially averaged for the $\mathrm{CH}$ and $\mathrm{KH}$ to create precipitation timeseries. To identify heavy precipitation events, we calculated the 85 th percentile of all non-zero precipitation days for winter seasons (DJFM) for both APHRODITE and TRMM. A minimum of 3 consecutive days below the 85 th percentile was required to characterize independent events. Of 85 th percentile events within 3 days of each other, only the maximum day was retained.
Fig. 2 (Left) Regions where TRMM heavy precipitation was investigated. Karakoram (white $b o x)$ and central Himalaya (red box). (Right) DJFM average total seasonal precipitation (mm) 1998-2010
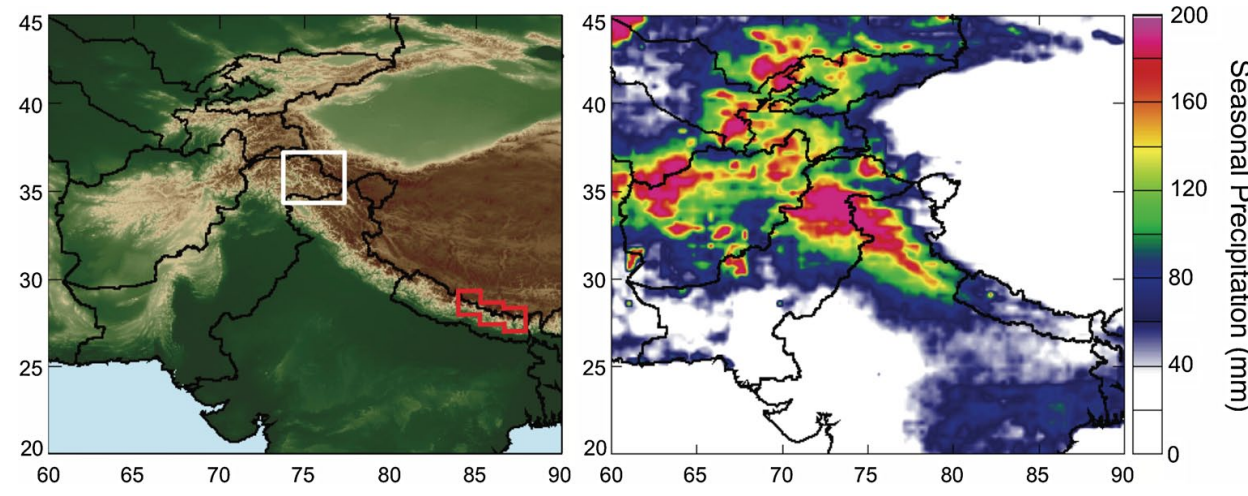
For validation, TRMM and APHRODITE precipitation timeseries were cropped to contain overlapping years (1998-2007). The daily temporal correlation coefficient between the TRMM and APHRODITE regional precipitation indices for the $\mathrm{CH}$ was 0.65 and 0.36 for the KH. The better correlation over the $\mathrm{CH}$ is likely attributable to the increased number of stations in APHRODITE. Also, the $\mathrm{KH}$ has a higher mean elevation than the $\mathrm{CH}$, which receives proportionally more rainfall in the foothills and river valleys during winter storms and is thus more visible to TRMM. For the $\mathrm{CH}$, this analysis produced 40 independent heavy precipitation days, which averaged to between 4 and 5 events per winter season (1998-2007). These 40 events accounted for less than $4 \%$ of total days evaluated, but contributed $50 \%$ of total seasonal precipitation. This is in accordance with Lang and Barros (2004), which observed CH winter snowfall accumulation to be primarily influenced by only a few events per season. Furthermore, to ascertain confidence in our heavy precipitation dates' contribution to solid-state precipitation at high elevation, we plotted JFM CH precipitation from APHRODITE and TRMM over snowfall accumulation timeseries from the Marsyandi Observation Network for the 2000, 2001, and 2002 winter seasons and found a very good qualitative relationship between our index of heavy precipitation events and large snow-accumulation events discussed in Lang and Barros (2004) (not shown). This analysis lends confidence to the use of TRMM and APHRODITE precipitation estimates for studying the timing of heavy precipitation events including snowfall over High Mountain Asia. We again note the caveat that we are assuming low-elevation precipitation is indicative of high-elevation snow, which does not hold true all of the time.

To extend this analysis, we used our heavy precipitation event methodology to identify the timing of events using APHRODITE from 1979-2007. 108 heavy precipitation events were identified in the $\mathrm{CH}$ and 90 in the $\mathrm{KH}$. This averages to between 3 and 4 events per winter season and accounts for roughly half of total seasonal precipitation in each region. The atmospheric conditions surrounding these events are further explored in subsequent sections.

\section{Atmospheric mechanisms: Himalaya heavy precipitation}

The relationship between WWD and heavy precipitation in the $\mathrm{KH}$ and $\mathrm{CH}$ was investigated using lag-composites of $200 \mathrm{hPa}$ upper-level geopotential height (H200) and vertically integrated meridional moisture flux anomalies (mean annual cycle removed). Figure 3 shows daily composites of
H200 (contours) and moisture flux (color) for the 90 heavy precipitation events selected for the $\mathrm{KH}$ region, 2 days prior to 2 days after the event.

The propagation of a deep synoptic trough toward the $\mathrm{KH}$, within a wave train positioned roughly along the zonal track of the $200 \mathrm{hPa}$ zonal jet, was observed over the course of 5 days, corresponding to the characteristic behavior of WWD. From day -2 to day 0 , the composite trough intensified and recorded statistically significant negative H200 anomalies as low as $-90 \mathrm{gpm}$ over eastern Afghanistan. Concomitantly, statistically significant positive meridional moisture flux exceeded $80 \mathrm{~kg} \mathrm{~m}^{-1} \mathrm{~s}^{-1}$ over the $\mathrm{KH}$ on day 0 . This indicated southerly moisture transport from the Arabian Sea into the $\mathrm{KH}$ by cyclonic circulation associated with the observed trough. Day-0 displayed a maximum in the H200 gradient between the trough to the west of the $\mathrm{KH}$ and a ridge over the Tibetan Plateau. The behavior of the trough and moisture transport after the heavy precipitation event indicated the rapid dissipation of the system. Over days 0 to +2 , the trough was observed to spread over the central Himalaya, but anomalies did weaken to non-significant levels. Additionally, negative H200 anomalies were observed over the majority of northern continental Asia, including Siberia, during the 5 day period.

Figure 4 displays the location of the center of statistically significant $\mathrm{H} 200$ anomalies for $\mathrm{KH}$ (left) and $\mathrm{CH}$ (right) heavy precipitation events. Comparison between composites indicated a difference in the positioning of the trough as well as differences in moisture transport and precipitation location. For the $\mathrm{KH}$ composite, moisture was advected from the Arabian Sea and penetrated well into the Karakoram. Maximum precipitation amounts were recorded in regions where the low-level flow was nearly perpendicular to the orographic barrier. This was also observed in the $\mathrm{CH}$ composite, where moisture-laden flow from the Arabian Sea and Bay of Bengal encountered topography at near right angles. Barros et al. (2006) showed through numerical simulation that low-level moisture laden flow approaching the $\mathrm{CH}$ lifts orographically to produce strong precipitation at steep angles of incidence.

In both cases, events are associated with the propagation of a midlatitude wave train (not shown); however, the $\mathrm{KH}$ trough weakened to non-significant levels (beyond day +2 ), suggesting that troughs associated with $\mathrm{KH}$ heavy events do not typically also produce $\mathrm{CH}$ heavy events. In fact, only 25 out of $108(\sim 23 \%)$ heavy precipitation events in the $\mathrm{CH}$ were preceded by a heavy precipitation event in the $\mathrm{KH}$ within 5 days (Fig. 5). Although the atmospheric processes responsible for heavy precipitation in these two regions in the winter are similar in nature and typically associated with the propagation of midlatitude wavetrains, significant precipitation events affecting the respective regions do not often occur from the same disturbance. 

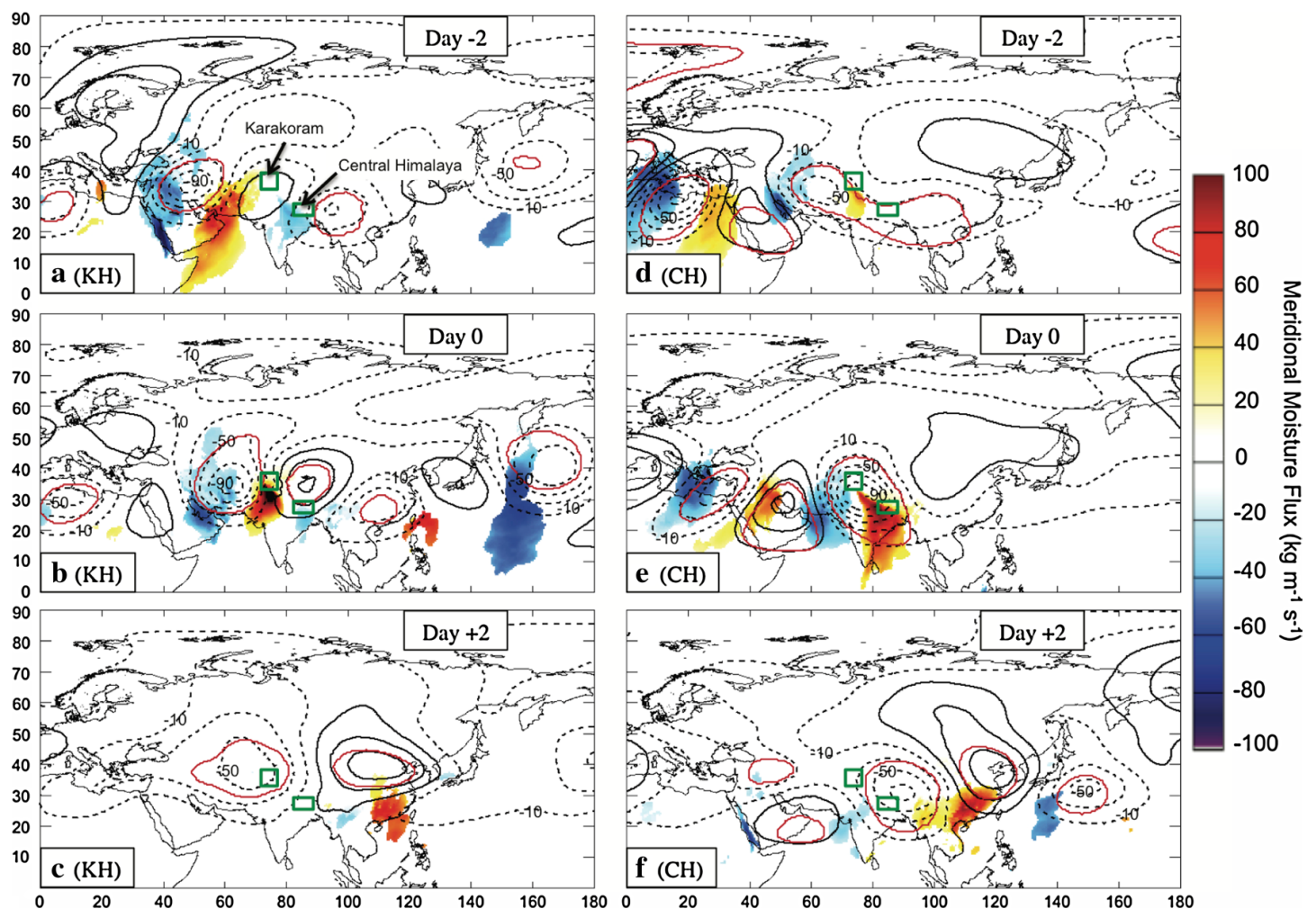

Fig. 3 Lag composites of $200 \mathrm{hPa}$ geopotential height (contour, m) and $95 \%$ significant vertically integrated meridional moisture transport (color, $\left.\mathrm{kg} \mathrm{m}^{-1} \mathrm{~s}^{-1}\right)$. Indexed 2 days prior heavy precipitation through 2 days after

Fig. 4 Lag composite day-0 of heavy precipitation events. $200 \mathrm{hPa}$ geopotential height anomaly center is indicated by red dot. Black outline indicates region of aggregated precipitation timeseries (KH on left, $\mathrm{CH}$ on right). Base layer is topography. Color displays standardized precipitation (composite mean minus average, divided by standard deviation). Vectors represent vertically integrated moisture flux
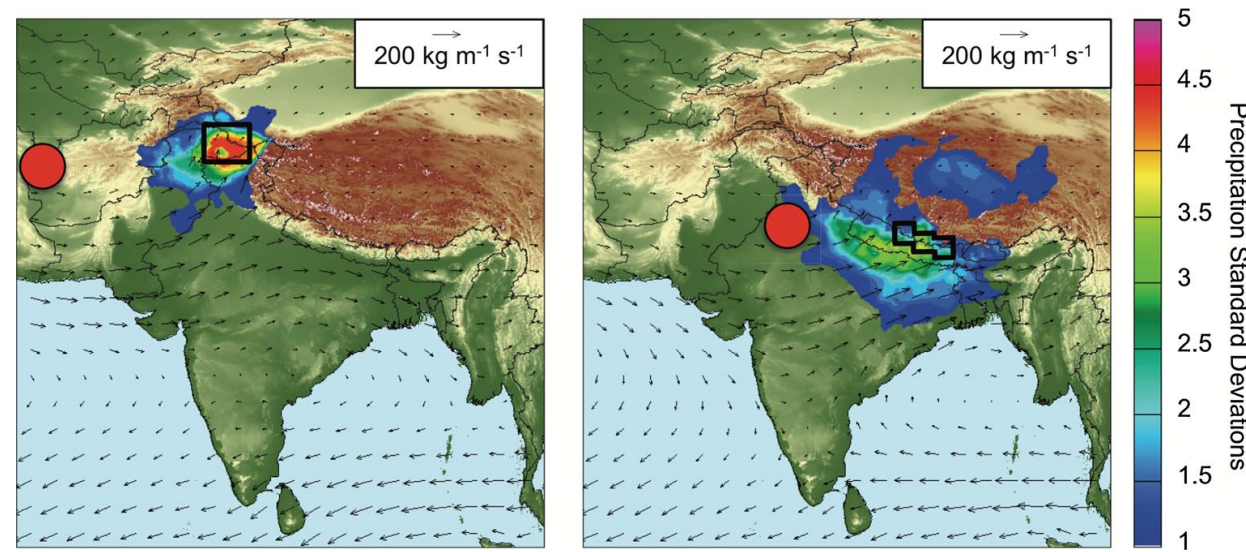

Himalaya topography plays a dominant role in modifying the circulation over Asia (Lang and Barros 2004). The mountain range may block approaching systems, thus modifying the storm track (Galewsky 2009). Lang and Barros (2004) observed that WWD affecting the Gangetic Plain and $\mathrm{CH}$ passed through a notch in topography between the Karakoram and Hindu Kush ranges. This diffraction is a phenomenon both dependent on the direction and strength of a system (Medina et al. 2005; Galewsky 2009). Our results indicate that it is not common for WWD to be channeled between the Hindu Kush and Karakoram ranges into the central Himalaya without significant weakening of the system. Often, disturbances encounter the KH orography and deposit large quantities of precipitation over the course of several days as the blocked system dissipates and/ or flows around the Tibetan Plateau. This is apparent in analyzing the spatial and temporal distribution of precipitation across the Himalaya. The Western Himalaya, Karakoram, Hindu Kush and Pamir Mountains receive considerably more WWD precipitation on average than the downstream 
Fig. 5 Light blue indicates number of heavy precipitation events in the $\mathrm{CH}$ per winter season. Dark blue indicates number of events per season that were preceded by a KH heavy precipitation event within 5 days
Fig. 6 (Top) $200 \mathrm{hPa}$ Geopotential height anomalies time series for $\mathrm{KH}(l e f t)$ and $\mathrm{CH}$ (right) central region of negative anomalies during day- 0 of heavy precipitation for the period 1979-2010. (Bottom) Wavelet power spectrum of respective time-series. Red lines indicate statistically significant variability. Light shading indicates power influenced by edge-effects
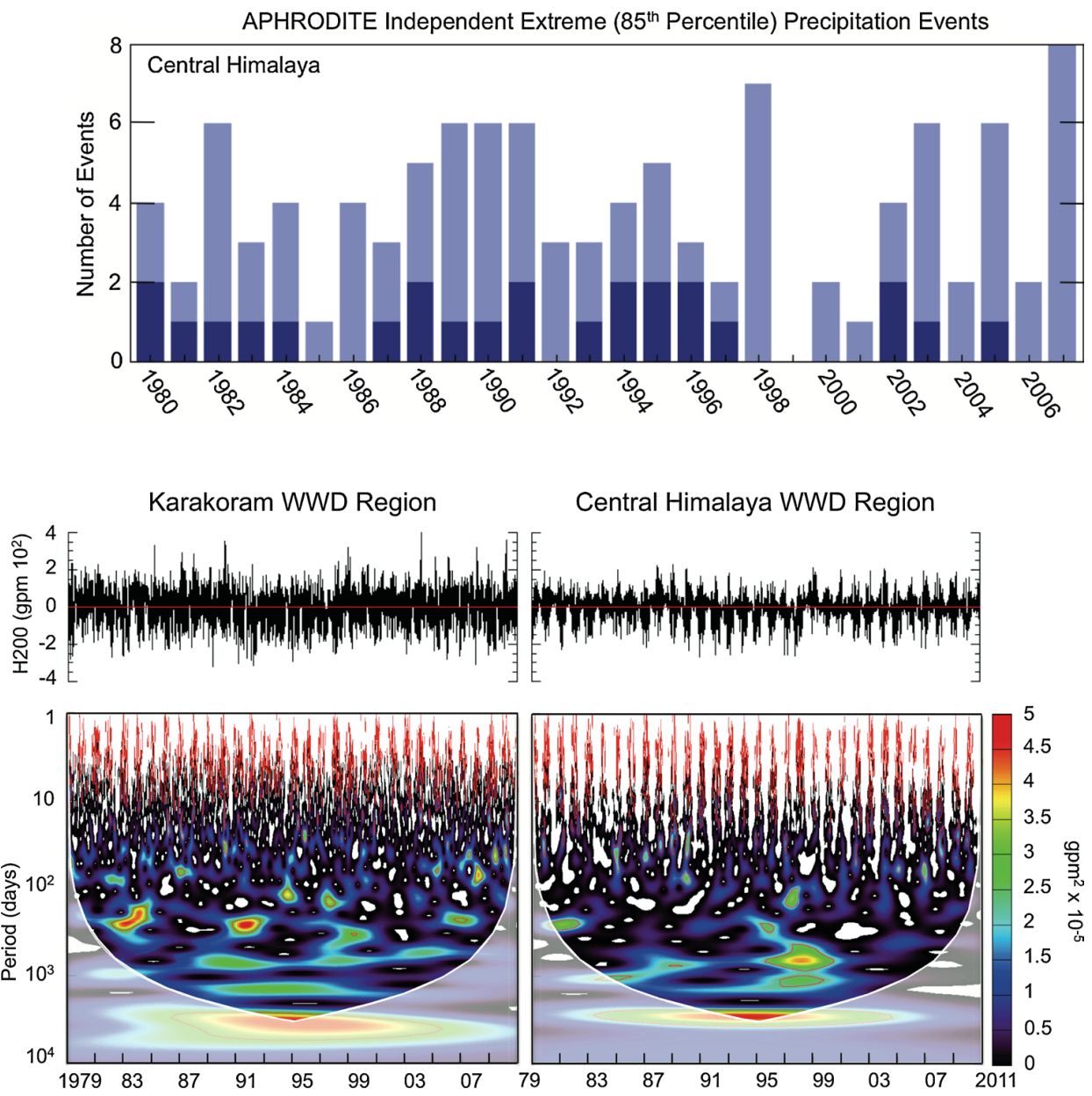

$\mathrm{CH}$ ranges (Fig. 2 right). In Sect. 5 we investigate multiannual WWD variability and examine the implications for regional precipitation over the period 1979-2010.

\section{Winter westerly disturbance activity}

The analyses of the atmospheric mechanisms associated with heavy precipitation events in the $\mathrm{KH}$ and $\mathrm{CH}$ regions raise an important question: has WWD activity changed in recent decades? Wavelet analysis was employed to investigate variations of the WWD power spectrum for the time period 1979-2010 (Torrance and Compo 1998). This method was applied to $\mathrm{H} 200$ anomalies as a proxy for WWD. Troughs and ridges that characterize these systems were identified by variations in $\mathrm{H} 200$ anomalies that manifested as significant power at the synoptic scale ( 216 days, Fig. 6). This analysis was performed over the central region where negative $\mathrm{H} 200$ anomalies occurred during day-0 of lag-composite analysis (Fig. 4) for heavy precipitation in the $\mathrm{KH}$ and $\mathrm{CH}$. In the $\mathrm{KH}$ case, $\mathrm{H} 200$ daily anomalies were averaged in the region $58-62^{\circ} \mathrm{E}, 32-36^{\circ} \mathrm{N}$, which lies approximately $15^{\circ}$ degrees to the west of the Karakoram. This corresponded to the trough's center at day- 0 , with the cyclone's leading edge stationed over the $\mathrm{KH}$ (not shown). For the $\mathrm{CH}$, the region $75-78^{\circ} \mathrm{E}, 28-30^{\circ} \mathrm{N}$ was used (observed as the center of negative anomalies in Fig. 4, right).

The resulting wavelet power spectrum of $\mathrm{H} 200$ recorded significant power (above the red-noise spectrum) at scales less than 16 days (Fig. 6). This high-frequency variability corresponds to the rapid passage of a trough, which is indicative of WWD activity and typically associated with heavy precipitation events in both the $\mathrm{CH}$ and $\mathrm{KH}$ (Lang and Barros 2004; Ridley et al. 2013). Figure 7 also illustrates key differences in $\mathrm{H} 200$ variability between the $\mathrm{CH}$ and $\mathrm{KH}$. The magnitude of daily $\mathrm{H} 200$ anomalies are relatively larger for $\mathrm{KH}$ compared to $\mathrm{CH}$ (Fig. 7, top), which translate to more power at higher frequencies. Differences between the $\mathrm{KH}$ and $\mathrm{CH}$ wavelet power spectra are not restricted to high frequencies. A notable aspect of the $\mathrm{CH}$ power spectrum is the 1997/98 El Niño to 1998/99 La Niña transition, which dominates frequencies corresponding to 2-3 year variations. In contrast, ENSO events during the 
Fig. 7 Total daily $200 \mathrm{hPa}$ geopotential height synoptic power (5-15 day) for winter seasons (DJFM). Seasonal averages displayed as blue line and 1979-2010 seasonal trend plotted as red line. (Top) central region of negative anomalies during $\mathrm{KH}$ heavy precipitation day-0. (Bottom) central Himalaya region. Trends are significant at 95 th percent confidence interval
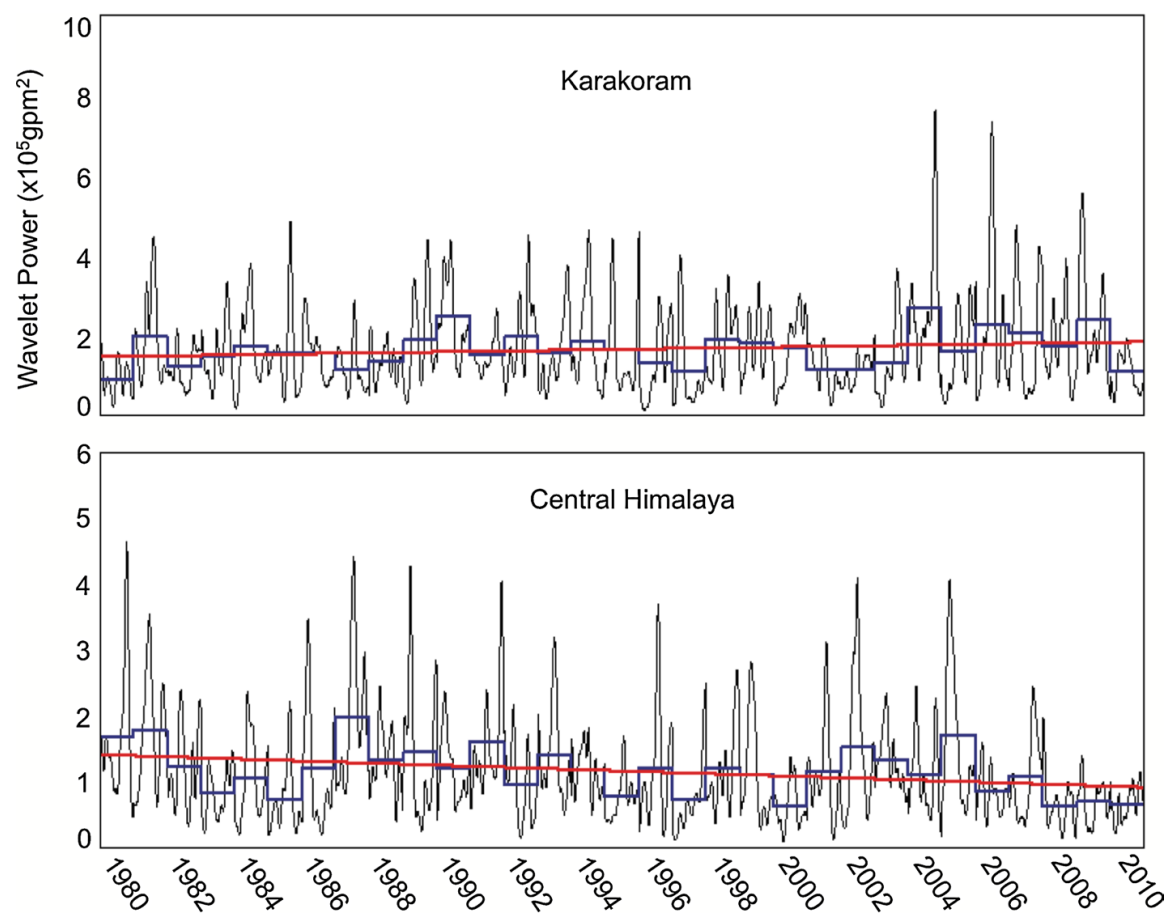

$82 / 83$ and 91/92 seasons produced a strong signal in $\mathrm{KH}$ climate at 1-2 year periods, while the 97/98 event appeared less influential for the region. To further investigate the interannual variability of WWD activity, we focused our analysis on the wavelet power frequencies corresponding to 2-16 days. The daily synoptic power was estimated as the total power within these frequencies.

Figure 7 displays the interannual variation of synoptic-scale $\mathrm{H} 200$ power for the KH. A positive trend was observed for the KH for the period 1979-2010. A statistical significance test was performed using Monte Carlo simulation (tests were performed for seasonal mean values to avoid autocorrelation) and indicated the linear trend coefficient to be significant at the $95 \%$ CI. The most remarkable increase in power in the $\mathrm{KH}$ was observed in the winter seasons of the last decade of observation (2001-2010), suggesting the strengthening of disturbances (Fig. 7). Contrastingly, the region affecting $\mathrm{CH}$ precipitation displayed a significant negative trend in $\mathrm{H} 200$ synoptic variability. Furthermore, this timeseries indicated a distinct decrease in the magnitude of the strongest events over the past decade.

Lang and Barros (2004) noted that the depth of systems producing $\mathrm{CH}$ precipitation was not linearly related to the amount of precipitation produced, but it is reasonable to infer that increased (decreased) variance in the synoptic scale at upper levels over the WWD track is conducive to more (less) precipitation in the regions affected by those WWD. We note that trends observed in the studied area over the studied period cannot be extrapolated to infer long-term climatic trends and should be interpreted as multiannual variations in WWD. From these results, it can be determined that WWD activity has increasingly favored KH events for the period 1979-2010. Contrastingly, the variance at synoptic scales in the region that produces $\mathrm{CH}$ heavy precipitation events has decreased in the same period.

Figure 8 displays composites of monthly means of daily precipitation (APHRODITE) for 85th percentile synoptic power index events minus composites of 15th percentile events for the KH (Fig. 8a) and CH (Fig. 8b). Figure $8 \mathrm{a}$ indicates that during months of strong synoptic activity in the $\mathrm{KH}$ region, precipitation increased significantly in the Karakoram, Hindu Kush and Pamir ranges, while the $\mathrm{CH}$ experienced a decrease in precipitation. Though differences in the KH are within a range of 0.5$2 \mathrm{~mm} /$ day, mean daily precipitation for the region is less than $5 \mathrm{~mm}$ per day during winter months, thus the relative contribution is meaningful $(\sim 10-40 \%$ of the climatology). Figure $8 \mathrm{~b}$ indicates that during increased WWD activity in the $\mathrm{CH}$, precipitation increased for the entire Himalaya. WWD pass between the Hindu Kush and Karakoram ranges to reach the $\mathrm{CH}$, thus producing precipitation in the $\mathrm{KH}$ as well as the $\mathrm{CH}$. In contrast, systems affecting the $\mathrm{KH}$ are often blocked from the $\mathrm{CH}$ resulting in a large difference in seasonal precipitation between regions. Our results indicate that WWD activity in the $\mathrm{KH}$ has increased in frequency and strength in recent decades, however, these systems have tended to be blocked from the $\mathrm{CH}$, thereby increasing the precipitation gradient between the $\mathrm{KH}$ and $\mathrm{CH}$. 

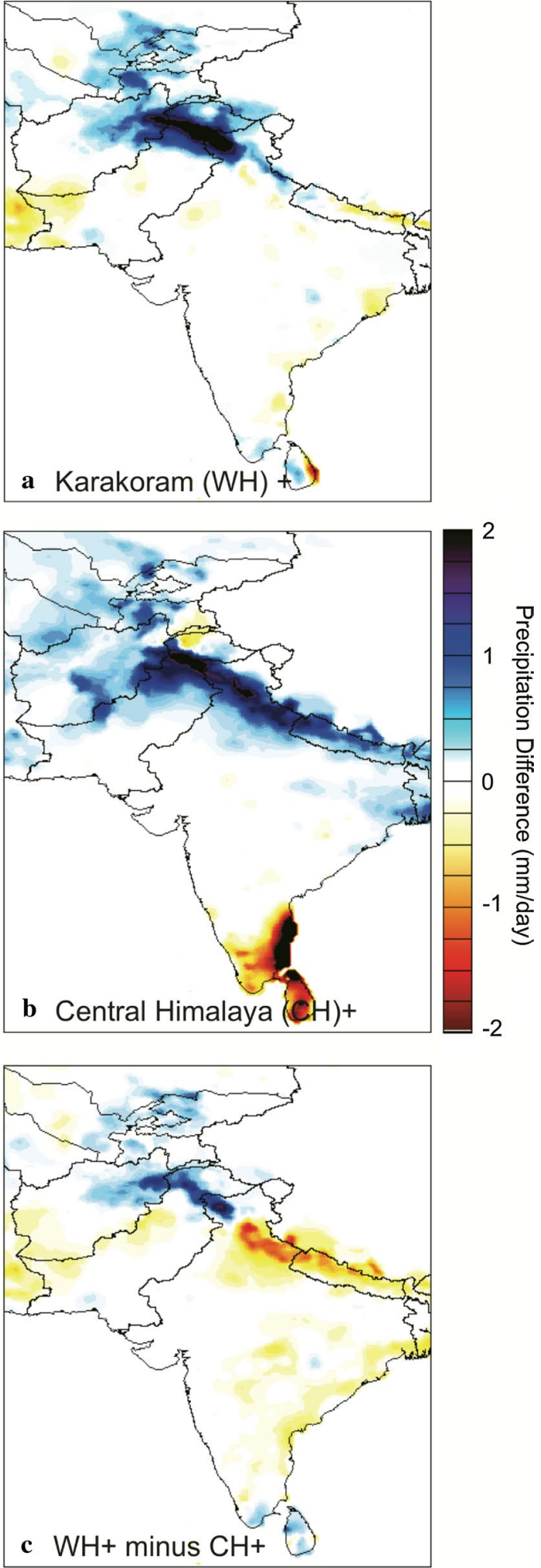

Fig. 8 Composites for monthly means of daily precipitation totals during 85th percentile synoptic power index months minus 15th percentile months. a Western Himalaya/Karakoram synoptic power index composite. b Central Himalaya index composite. c Western Himalaya 85th percentile composite minus central Himalaya 85th percentile composite
The observed trends in the synoptic scale portion of the wavelet power spectrum at individual locations is compelling, but investigating the spatial behavior of this variability is important to further understand the large-scale mechanisms and teleconnections. To address these issues, we performed wavelet analyses of daily $\mathrm{H} 200$ anomalies $(1979-2010)$ at $2^{\circ}$ spatial resolution over Asia $\left(0-180^{\circ} \mathrm{E}\right.$, $\left.0-90^{\circ} \mathrm{N}\right)$. Frequencies corresponding to the synoptic scale (2-16 days) were selected and summed to produce a quantitative estimate of the total synoptic power at an individual location through time. Linear trends in wintertime synoptic power from 1979-2010 DJFM over Asia were then computed (Fig. 9). Results indicated decreasing power at highlatitudes and increasing power in the mid-latitudes at the synoptic scale. The trends are largely zonal and this pattern reflects a change in the geopotential height gradient and sub-tropical jet across the northern hemisphere (Sect. 6). A northerly shift in the jet would likely produce a northerly shift in WWD storm tracks, forcing the systems to interact differently with Himalayan topography and possibly shadowing the $\mathrm{CH}$ for a greater proportion of WWD activity. Performing this methodology at $1^{\circ}$ resolution over the Himalaya $\left(60-90^{\circ} \mathrm{E}, 20-50^{\circ} \mathrm{N}\right)$ displayed a strong dipole between the central region of negative $\mathrm{H} 200$ anomalies for Karakoram WWD and CH WWD (Fig. 10). Over the time period 1979-2010 the geographic location corresponding to the central region of negative $\mathrm{H} 200$ anomalies associated with $\mathrm{KH}$ heavy precipitation has experienced a significant increase in H200 synoptic power associated with WWD activity. In contrast, the corresponding $\mathrm{CH}$ region has experienced a significant decrease in WWD activity.

\section{Multi-annual variations in the midlatitude jet and implications for synoptic activity}

Multi-annual variations in synoptic activity affecting the Himalaya are likely connected to changes in circulation affecting regional to large-scale climate patterns. Variability of the midlatitude jet is attributable to heat and mass exchanges within the troposphere and the distribution of potential and kinetic energy at the global scale. The $200 \mathrm{hPa}$ zonal wind climatology (U200) for the winter season (DJFM) $1979-2010$ for the domain $0-180^{\circ} \mathrm{E}, 0-90^{\circ} \mathrm{N}$ is displayed in Fig. 11a. Statistically significant $(5 \% \mathrm{CI})$ linear trend coefficients of anomalies are displayed in Fig. 11b, and indicate an increase in the magnitude of midlatitude U200 westerlies immediately north of the climatological mean of the jet. Figure 11c displays 8-year mean extents of U200 $50 \mathrm{~ms}^{-1}$ isotach during DJFM for the period 1979-2010. The 8-year window was conveniently chosen to divide the period into equal intervals, each one with approximately the same number of El Nino and La 
Fig. 9 1979-2010 linear trend coefficients for DJFM seasonal averages of total daily $200 \mathrm{hPa}$ geopotential height synoptic power (5-15 day). Contours show statistically significant trends at $90 \%$ or higher confidence interval

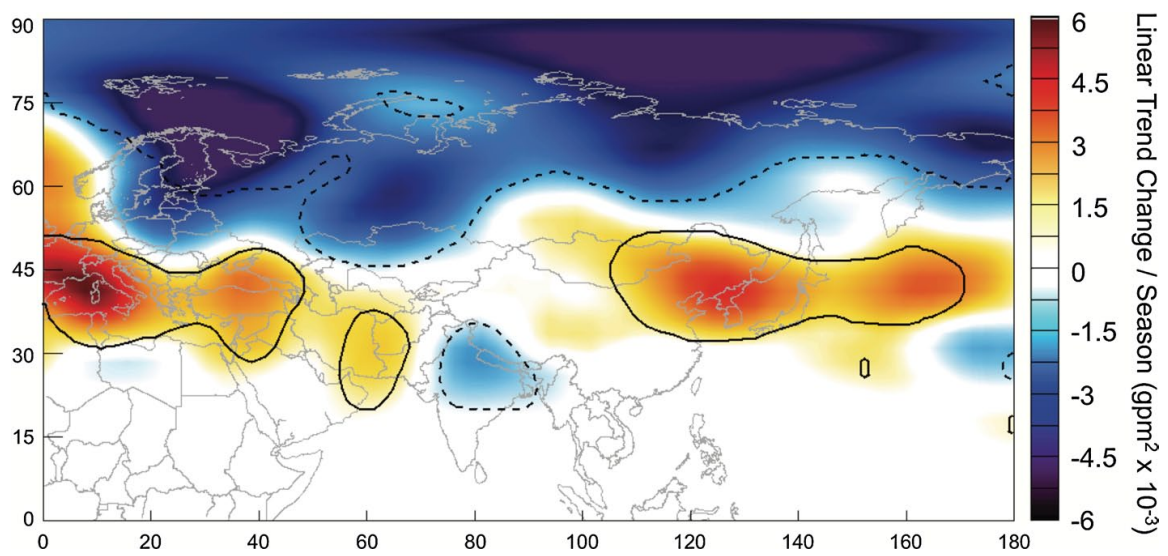

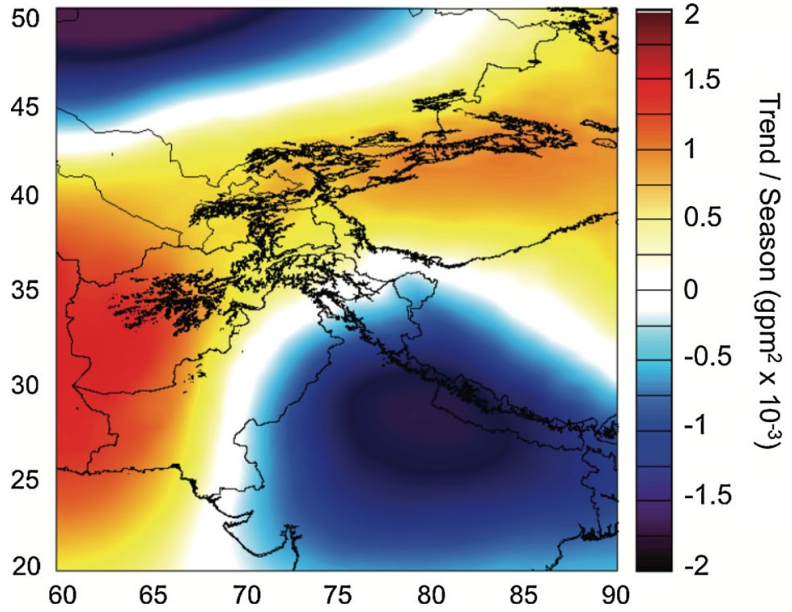

Fig. 1030 -year trends of total daily $200 \mathrm{hPa}$ geopotential height synoptic power (5-15 day) DJFM. 3000 m-elevation contour is plotted to show High Asia topography
Nina Episodes. Figure 11c clearly indicates that the magnitude and position of the jet's core have varied in a nonlinear way. The maximum 8-year mean extent was recorded for the period 1995-2002, while the minimum was observed during 1979-1986. A northward and westward shift of the $50 \mathrm{~m} / \mathrm{s}$ isotach is also evident in the last decade. The strength and position of the westerly jet over Asia have likely influenced the propagation of WWD (Dimri 2006). Observed increases in KH WWD activity may be attributable to an increase in the relative strength of U200 in the late nineties that was sustained until present.

Undulations in the westerly jet play a significant role for high and low-pressure systems, and therefore determine the strength and position of WWD over Asia (Krishnamurti 1961; Ridley et al. 2013). For instance, Dimri (2006) found an intensification of the subtropical westerly jet stream during surplus precipitation years in the $\mathrm{KH}$ for the years 1958-1997. Thus, the observed trend in the jet appears to
Fig. 11 a $200 \mathrm{hPa}$ zonal wind climatology DJFM 1979-2010. b $200 \mathrm{hPa}$ zonal wind linear trend coefficient per season DJFM 1979-2010 (90 \% significant values only). c 8-year mean $200 \mathrm{hPa}$ zonal wind greater than $50 \mathrm{~m} / \mathrm{s}$ corresponding to the jet core DJFM 19792010. The following number of EL Nino (EN) and La Nina (LN) events was recorded in each 8-year period: 1979-1986 (1 EN and 2 LN); 1987-1994 (2 EN and $1 \mathrm{LN}$ ); 1995-2002 (2 EN and 2 LN); 2003-2010 (4 EN and $3 \mathrm{LN}$ ). Source: http://www.cpc.ncep.noaa.gov/
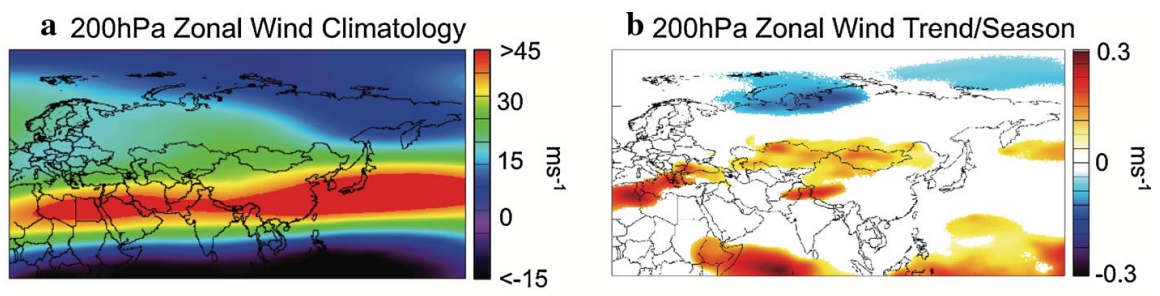

c $200 \mathrm{hPa}$ Zonal Wind $>50 \mathrm{~ms}^{-1}$

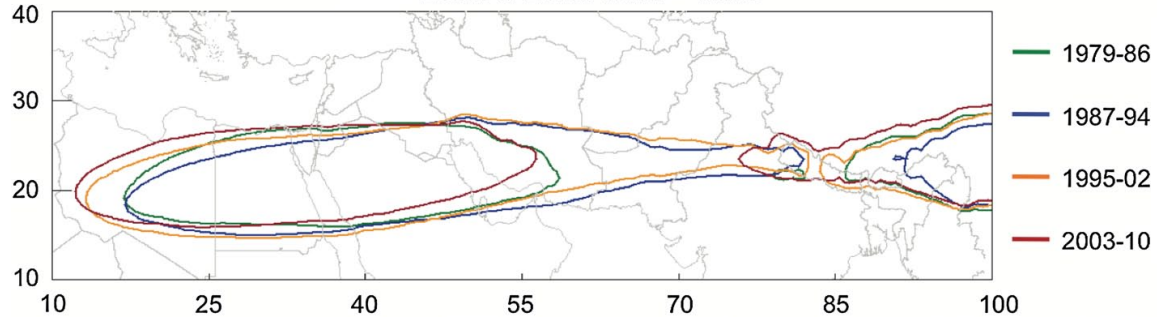


have contributed to the enhancement of WWD affecting the $\mathrm{KH}$ as well as how these systems behave upon encountering the Himalaya. Medina et al. (2005) observed that disturbances approaching the European Alps were funneled by topography to the region of maximum concavity. This phenomenon seems to be active in the Himalaya as well, and allows WWD approaching topography to find a notch between the Karakoram and Hindu-Kush Mountains. However, as storm tracks take a more northerly route due to the changing position of the jet, the central Himalaya may be increasingly shadowed. Wavelet analysis of H200 at the synoptic scale (Fig. 9) is consistent with this hypothesis as it showed an increase in activity approaching the Karakoram and also an increase to the northeast, while the central Himalaya recorded a drastic decrease in synoptic variability. Also, the zonal strengthening trend of westerlies has occurred at the same latitude as the zonal strengthening in H200 synoptic power (compare Figs. 9, 11).

\section{Teleconnections}

Multiannual variations in synoptic scale activity may have strong and non-linear relationships with low-frequency coupled modes on a broad range of scales. As discussed earlier, the El Niño Southern Oscillation (ENSO), Arctic Oscillation (AO), Siberian High $(\mathrm{SH})$, and Eurasian/ Polar Pattern (EP) are among the dominant modes of climate variability, with time scales ranging from months to years, which have been related to climatic impacts in Asia
(Cohen and Entekhabi 1999; Wu and Wang 2002a, b; Gong and Ho 2002). Thus, investigating these modes is essential to understanding the interannual-to-decadal variability of Himalayan climate.

Figure 12 illustrates the complexity of relationships between the AO, SH, PE and the Multivariate ENSO (MEI: Wolter and Timlin 2011) indices. Seasonal averages of the four monthly indices (line) are plotted over H200 synoptic power for the KH (bars) for the period 1979-2010. No single mode indicated a direct linear relationship with WWD power for the $\mathrm{KH}$, though the positive phase of the AO was significantly correlated $(p<0.05)$ with $\mathrm{KH}$ synoptic WWD power. In addition, Fig. 12a, b also reveal a notable changepoint in both the AO and SH indices around 1989. A linear trend of pre-1989 seasons was plotted alongside a comparative trend for post-1989 seasons to indicate an apparent shift in the decadal behavior of the $\mathrm{AO}$ and $\mathrm{SH}$ modes. For the majority of the past two decades, the AO has tended to remain in the positive phase. However, the mode has been trending negatively over that time period and over the past decade has averaged to a neutral phase (Fig. 12a). In contrast, the $\mathrm{SH}$ has strengthened since its minimum in 1989 (Fig. 12b). As noted in the introduction, this relationship may result from feedbacks between northern hemisphere modes of atmospheric variability (Takaya and Nakamura 2005). The AO and SH post-1989 trends and PE 1979-2010 trend were significant $(p<0.05)$ based on Monte Carlo simulation.

The negative phase of the AO is characterized by positive sea-level pressure anomalies in the Arctic and negative
Fig. 12 Standardized wintertime teleconnections indices: a Siberian High, b Arctic Oscillation, c Polar/Eurasian Pattern and $\mathbf{d}$ ENSO MEI. Red dashed lines in (a) and (b) are linear trend fit from 1980-1990 and blue dashed lines are linear fit from 1990-2010. The red dashed line in (c) and (d) shows the linear fit from 1980-2010. The mean seasonal KH synoptic power is shown as gray shaded bars

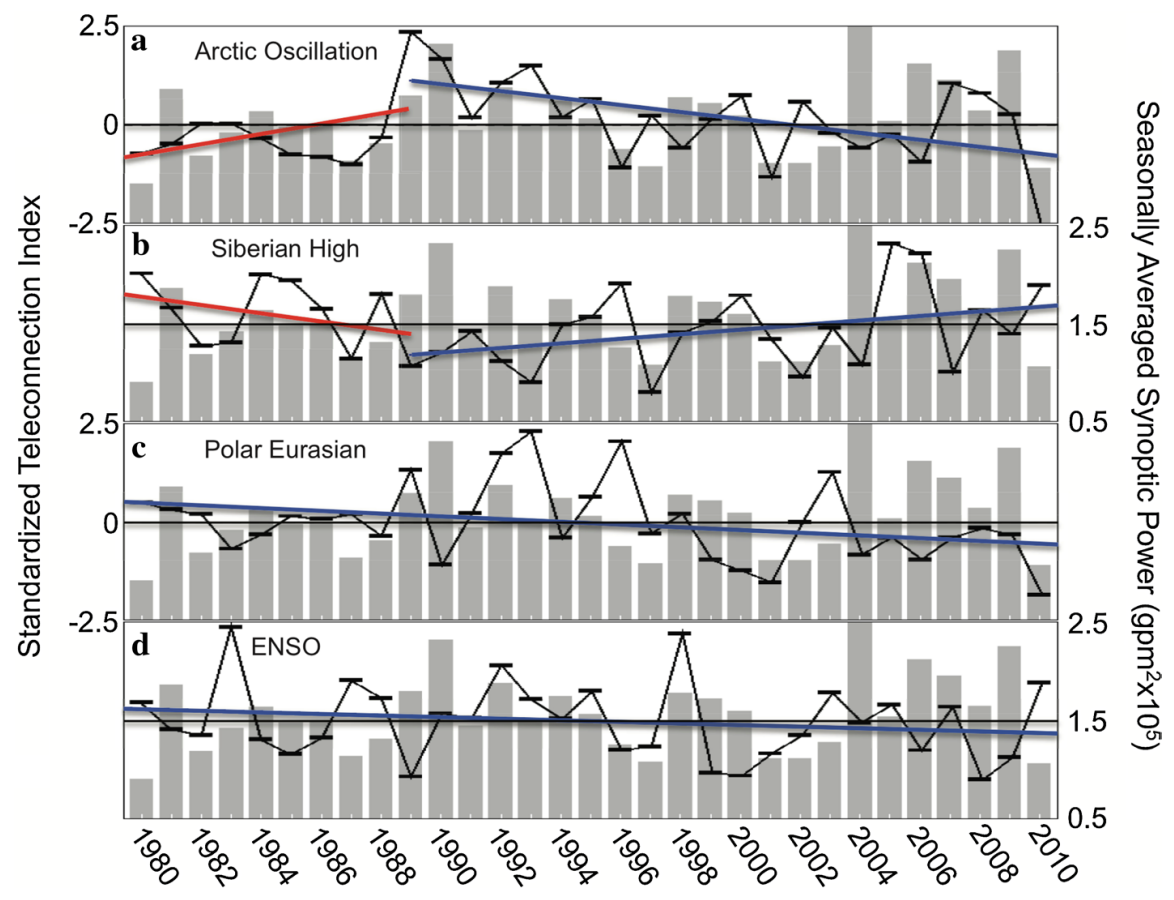


Fig. 13 (Left) monthly $200 \mathrm{hPa}$ zonal wind anomaly composite for 85th percentile (positive) Siberian High (a, e), Arctic Oscillation $(\mathbf{b}, \mathbf{f})$, Polar Eurasian $(\mathbf{c}, \mathbf{g})$ and El Niño MEI (d, h) events. (Right) monthly APHRODITE precipitation composites for 85 th percentile minus 15 th percentile teleconnection events. Solid (dashed) contours indicate significant positive (negative) values

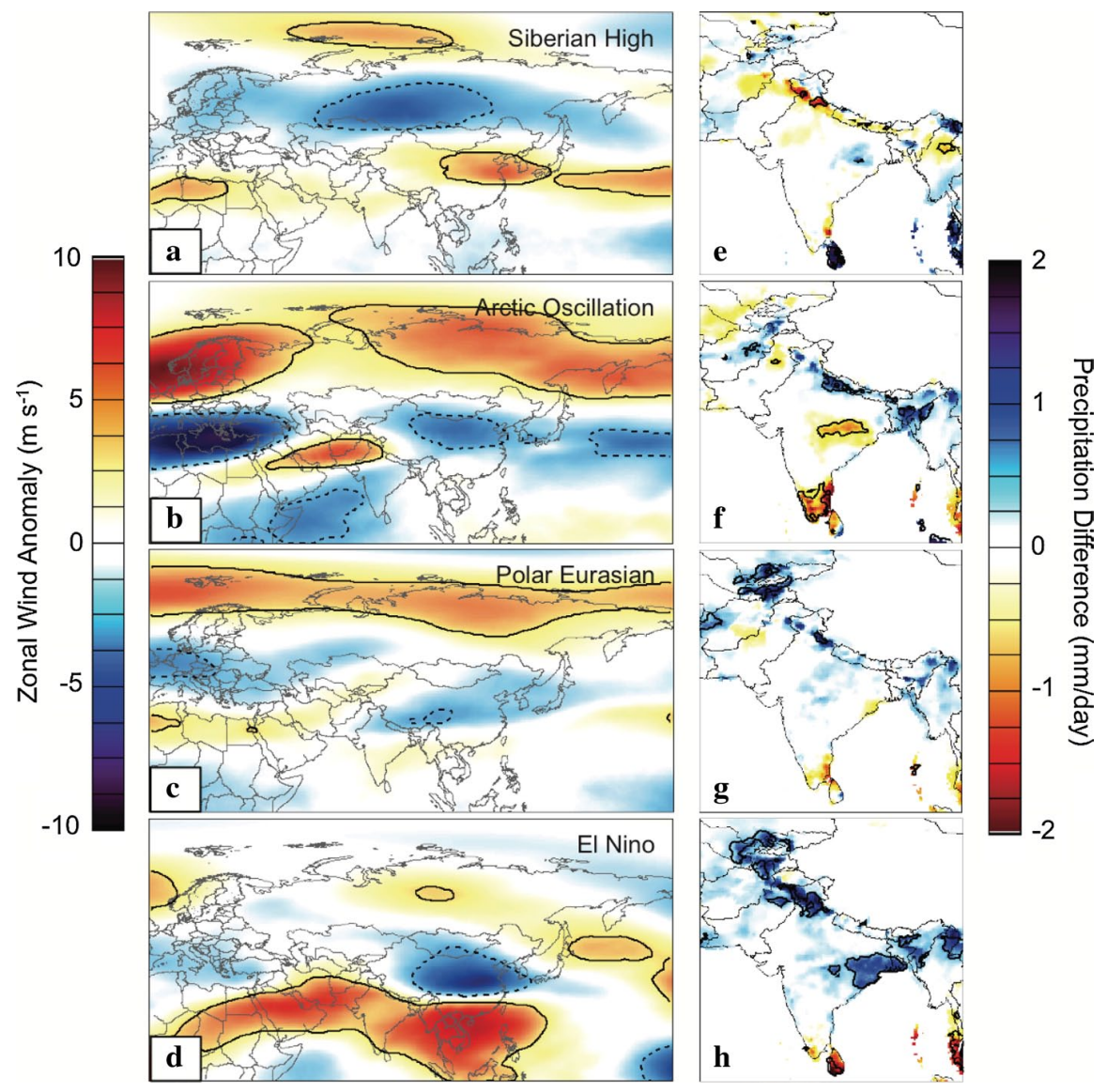

pressure anomalies in mid-latitudes, which translates to positive $\mathrm{H} 200$ anomalies at polar latitudes and negative anomalies in the mid-latitudes, thus weakening the climatological pressure gradient (Thompson and Wallace 1998). Consequently, the upper level winds weaken as well, thereby inducing large undulations in the jet and allowing the southerly propagation of cold Arctic air masses (Greene and Monger 2012). Figure 13b shows composites of seasonal $200 \mathrm{hPa}$ zonal wind (U200) anomalies during the 85 th percentile (positive phase) of the index. The signal of the AO is centered over Europe, upstream of the Himalaya. Changes in the strength of westerlies are observed with latitude. During the AO positive phase, the eastern extent of the subtropical jet shifted northward (Fig. 13b). Additionally, the region of the jet to the west of the Karakoram experienced a significant increase in magnitude. The location and intensity of the jet strongly influences large-scale dynamical processes in mid-latitudes (Vallis and Gerber 2008), and serves as a wave-guide, bridging atmospheric variability upstream of High Mountain Asia to regional climate (Zhu et al. 2011). The strengthening of U200 over the Himalaya is associated with enhanced WWD activity (Yadav et al. 2009). Figure 13(right column) displays APHRODITE derived mean monthly precipitation composites for 85th percentile (positive) index minus 15th percentile (negative) for the period 1979-2007. Figure 13f indicates an increase in $\mathrm{CH}$ precipitation for winter seasons during the positive phase of the AO. Increased precipitation over northwest India during positive AO was also observed by Yadav et al. (2009).

In accordance with Lang and Barros (2004), we found the Polar/Eurasian pattern to significantly affect Himalaya climate. A strengthening of the circumpolar vortex during the positive phase is known to restrict cold-air outbreaks over North-America and Europe. However, our results indicate that the climatological upper-level high over northern Eurasia during the positive phase is balanced by a $200 \mathrm{hPa}$ negative center over southern Europe and the Middle East. The southern boundary of this region of negative anomalies is co-located with the mid-latitude jet and serves to intensify westerly wind. Enhanced divergence aloft in this region is likely related to increased WWD activity and precipitation over High Mountain Asia, as seen in Fig. 13g.

Figure 13a displays weakened upper level westerlies over Siberia during the SH positive phase. To the south of the SH, U200 increased, while the region corresponding to the position of WWD storm tracks entering the Himalaya displayed enhanced U200. Strengthening of the high 
modifies WWD propagation by restricting their flow to more southerly latitudes. In this case, the blocking high over Eurasia is constrained orographically by the Tibetan Plateau to its south and is forced to spread west, thereby restricting disturbances to a weaker, more southern track. Conversely, the weakening of the mode allows for systems to propagate unimpeded, and is associated with intensified WWD activity in the KH. Figure $13 \mathrm{e}$ shows that during the negative phase of the $\mathrm{SH}$, precipitation in the $\mathrm{CH}$ increases approximately $0.5 \mathrm{~mm}$ /day based on monthly averages.

The MEI warm-phase has been linked to precipitation increases in the western Himalaya during winter (Yadav et al. 2010). Figure 13d shows an increase in U200 over southern Asia. This is attributable to increased subsidence over the maritime continent, which intensifies convergence over southeastern Asia, both strengthening the jet and delaying its northward seasonal migration (Yadav et al. 2010). Figure $13 \mathrm{~h}$ shows the associated increase in precipitation for the entire Himalaya region, with particular significance in the KH during El Niño events. This result seems to contradict the below-average synoptic power observed during the 1982-83 and 1997-98 ENSO events (Fig. 12d). The wavelet power spectrum within the Himalaya (Fig. 6) is distributed at varying frequencies and also changes spatially, thus we would not necessarily expect to see a direct relationship between the MEI and synoptic geopotential height power. Additionally, the 1982-83 ENSO event produced significant power in the KH, while the 1997-98 event was not observed to affect regional H200 power at the same spectral band as strongly.

\section{Conclusions}

The objective of this research was to investigate the spatiotemporal linkages among regional precipitation and largescale circulation in High Mountain Asia. Our analysis relies on remotely sensed (TRMM-3B42) and ground interpolated precipitation (APHRODITE), and on reanalysis data (CFSR). We observed differences in circulation between central Himalaya $(\mathrm{CH})$ and western Himalaya/Karakoram (KH) heavy precipitation events, which evidenced that though systems producing significant precipitation in the two regions are dynamically similar, recorded events in the two study regions do not typically occur from the same Winter Westerly Disturbance (WWD).

Wavelet power spectrum analysis of $200 \mathrm{hPa}$ geopotential height (H200) anomalies indicated differing trends in synoptic scale variability across High Mountain Asia. The zonal track of WWD to the west of the Himalaya experienced an increase in the magnitude of individual events since 1979. Specifically, the synoptic power spectrum for the region corresponding to the center of the WWD trough affecting the $\mathrm{KH}$ during day-0 of lag-composite analysis experienced an intensification of activity for the period 1979-2010 with the strongest increase produced by several high-magnitude events from 2003-2010. In contrast, the region corresponding to $\mathrm{CH}$ WWD activity observed a significant negative trend since 1979. The dipole in WWD activity trends between the respective locations of upperlevel troughs that are responsible for heavy precipitation in the $\mathrm{KH}$ and $\mathrm{CH}$ likely elicited changes in regional precipitation patterns. We speculate that these trends were elicited by changes in large-scale circulation, which intensified WWD activity, but altered the storm track to reduce the number of orographically captured events affecting the $\mathrm{CH}$. Our analysis builds on that of Lang and Barros (2004), which identified a link between heavy winter precipitation and a depression in upper-level geopotential height over a notch between the Hindu Kush and Karakoram ranges. The use of geopotential height variability at the synoptic scale as a WWD proxy is justified by the relationship between precipitation and circulation, though it is noted that the relationship is not linear. This is attributable to the complex dynamics of individual extratropical cyclones interacting with topography, which is not accounted for in our approach.

We observed the wintertime subtropical jet to have intensified in the late $80 \mathrm{~s}, 90 \mathrm{~s}$ and early $00 \mathrm{~s}$, as well as to have shifted northward. Notably, a positive linear trend in the westerlies was observed over the period 1979-2010 to the north of the climatological mean of the subtropical jet and may indicate restricted southward migration of the jet during winter. In addition, the core of the jet was observed to be strongest during the 8-year mean spanning 1995-2002 and has remained comparatively strong with respect to the 8-year means for 1979-1986 and 1987-1994. This modification appears to have altered the propagation of WWD into High Mountain Asia. The intensification of the jet would increase WWD activity in the Karakoram, while the northward shift would alter the geometry of these systems to be more prone to orographic blocking by $\mathrm{KH}$ mountain ranges. The $\mathrm{CH}$ appears to have been increasingly shadowed from enhanced WWD activity in recent decades.

This study further examined linkages between synoptic power of the upper level geopotential height field, precipitation, and upper tropospheric circulation as modified by the main modes of climate variability affecting Asia on interannual timescales. The Siberian High (SH), the Arctic Oscillation (AO), Polar/Eurasian Pattern (PE), and the El Niño-Southern Oscillation (ENSO) were investigated with regard to High Mountain Asia climate. Although the relationships between these modes and WWD propagation are complex, their signatures in the upper-level jet and regional precipitation clearly evidence the importance of their multiannual variability for the observed trends in $\mathrm{KH}$ and $\mathrm{CH}$ synoptic power. 
Positive phases of the AO and PE are associated with intensifications of upper-level zonal westerlies. Though the dynamics differ, 85th percentile composites for both modes indicate a strengthening of the mid-latitude jet in the region of WWD activity and increased precipitation in High Mountain Asia. In contrast, the positive phase of the $\mathrm{SH}$ is linked to decreased precipitation in our study region, which is likely attributable to strong blocking of large-scale circulation by the low-level thermal high.

Feedbacks between modes complicate the understanding of general circulation and High Mountain Asia climate. A significant negative relationship between the $\mathrm{AO}$ and $\mathrm{SH}$ was observed, while the PE tended to be in phase with the AO. After 1989 the AO index was profoundly positive with decreasing strength into the 2000s. The strong positive (negative) phase of the $\mathrm{AO}$ and $\mathrm{PE}$ (SH) appears related to strengthened WWD activity in the Himalaya and is associated with increased precipitation. Additionally, composites of precipitation during El Niño/La Niña events indicated increased precipitation and the delayed northward migration of the jet during the index's warm-phase. This association was not readily apparent through a comparison between WWD synoptic power based on geopotential height variability and the ENSO index, which indicates the importance of investigating how ENSO cascades into higher frequency variations as well as the spatially differing responses during ENSO events. These issues are beyond the scope of this article.

Future work toward understanding the influence of the $\mathrm{SH}, \mathrm{AO}, \mathrm{PE}$ and ENSO is necessary to further understanding of external influences on High Mountain Asia climate. There is little doubt that these modes do modulate the propagation of WWD, but a full investigation accounting for their varying state as well as the frequencies at which their influence manifests is required. Understanding linkages between High Mountain Asia climate and the global atmosphere will improve projections of regional WWD variability into future decades and minimize uncertainty surrounding Asia's water resources.

Acknowledgments This research was supported by the Climate and Large-scale Dynamics Program, from the National Science Foundation (NSF award-AGS 1116105) and by NASA Headquarters under the NASA Earth and Space Science Fellowship Program (Grant Number 13-EARTH13F-26). The CFSR data used in this research were developed by NOAA's National Centers for Environmental Prediction (NCEP) and provided by NCAR. APHRODITE Water Resources project is supported by Environment Research \& Technology Development Fund of the Ministry of the Environment, Japan. TRMM data were acquired by an international joint project sponsored by the Japan National Space Development Agency (NASDA) and the U.S. National Aeronautics and Space Administration (NASA) Office of Earth Science. The Authors would also like to thank Dr. George Kiladis and Dr. Rodrigo Bombardi for their help throughout this project.

\section{References}

Archer DR, Fowler HJ (2004) Spatial and temporal variations in precipitation in the Upper Indus Basin, global teleconnections and hydrological implications. Hydrol Earth Syst Sci Discuss 8:47-61

Barlow M, Wheeler M, Lyon B, Cullen H (2005) Modulation of daily precipitation over southwest Asia by the Madden-Julian oscillation. Mon Weather Rev 133:3579-3594

Barros AP, Joshi M, Putkonen J, Burbank DW (2000) A study of the 1999 monsoon rainfall in a mountainous region in central Nepal using TRMM products and rain gauge observations. Geophys Res Lett 27:3683-3686

Barros AP, Chiao S, Lang TJ, Burbank D, Putkonen J (2006) From weather to climate-seasonal and interannual variability of storms and implications for erosion processes in the Himalaya. Geol Soc Am Spec Pap 398:17-38

Bhutiyani MR, Kale VS, Pawar NJ (2010) Climate change and the precipitation variations in the northwestern Himalaya: 18662006. Int J Climatol 30:535-548

Bolch T et al (2012) The state and fate of Himalayan glaciers. Science 336:310-314

Bookhagen B (2010) Appearance of extreme monsoonal rainfall events and their impact on erosion in the Himlaya. Geomat Nat Hazards Risk 1:37-50

Bookhagen B, Burbank DW (2010) Towards a complete Himalayan hydrological budget: the spatiotemporal distribution of snow melt and rainfall and their impact on river discharge. J Geophys ResEarth 115:1-25

Bothe O, Fraedrich K, Zhu XH (2012) Tibetan Plateau summer precipitation: covariability with circulation indices. Theor Appl Climatol 108(293):300

Cohen J, Entekhabi D (1999) Eurasian snow cover variability and Northern Hemisphere climate predictability. Gephys Res Lett 26:345-348

Cohen J, Saito K, Entekhabi D (2001) The role of the Siberian high in northern hemisphere climate variability. Geophys Res Lett 28:299-302

Cohen J, Barlow MA, Kushner P, Saito K (2007) Stratospher-troposphere coupling and links with Eurasian land-surface variability. J Clim 20:5335-5343

Dimri AP (2006) Surface and upper air fields during extreme winter precipitation over the western Himalayas. Pure Appl Geophys 163:1679-1698

Dimri AP, Dash SK (2012) Wintertime climatic trends in the western Himalayas. Clim Change 111:775-800

Galewsky J (2009) Rain shadow development during the growth of mountain ranges: an atmospheric dynamics perspective. J Geophys Res-Earth 114:1-17

Gardelle J, Berthier E, Arnaud Y (2012) Slight mass gain of Karakoram glaciers in the early twenty-first century. Nat Geosci 5:322-325

Gong DY, Ho CH (2002) The Siberian High and climate change over middle to high latitude Asia. Theor Appl Climatol 72:1-9

Gong DY, Wang SW, Zhu JH (2001) East Asian winter monsoon and Arctic Oscillation. Geophys Res Lett 28:2073-2076

Greene CH, Monger BC (2012) Rip current news in oceanography an Arctic wild card in the weather. Oceanography 25:7-9

Huffman GJ et al (2007) The TRMM multisatellite precipitation analysis (TMPA): quasi-global, multiyear, combined-sensor precipitation estimates at fine scales. J Hydrometeorol 8:38-55

Kaab A, Berthier E, Nuth C, Gardelle J, Arnaud Y (2012) Contrasting patterns of early twenty-first-century glacier mass change in the Himalayas. Nature 488:495-498

Krishnamurti TN (1961) The subtropical jet stream of winter. J Meteorol 18:172-191 
Lang TJ, Barros AP (2004) Winter storms in the central Himalayas. J Meteorol Soc Jpn 82:829-844

Medina S, Smull BF, Houze RA, Steiner M (2005) Cross-barrier flow during orographic precipitation events: results from MAP and IMPROVE. J Atmos Sci 62:3580-3598

Palazzi E, von Hardenberg J, Provenzale A (2013) Precipitation in the Hindu-Kush Karakoram Himalaya: observations and future scenarios. J Geophys Res-Atmos 118:85-100

Panagiotopoulos F, Shahgedanova M, Hannachi A, Stephenson DB (2005) Observed trends and teleconnections of the Siberian High: a recently declining center of action. J Clim 18:1411-1422

Rasmussen R et al (2012) How well are we measuring snow? The NOAA/FAA/NCAR winter precipitation test bed. B Am Meteorol Soc 93:811-829

Ridley J, Wiltshire A, Mathison C (2013) More frequent occurrence of westerly disturbances in Karakoram up to 2100. Sci Total Environ. doi:10.1016/j.scitotenv.2013.03.074

Saha $\mathrm{S}$ et al (2010) The NCEP climate forecast system reanalysis. B Am Meteorol Soc 91:1015-1057

Scherler D, Bookhagen B, Strecker MR (2011) Spatially variable response of Himalayan glaciers to climate change affected by debris cover. Nat Geosci 4:156-159

Singh P, Ramasastri KS, Kumar N (1995) Topographical influence on precipitation distribution in different ranges of western Himalayas. Nord Hydrol 26:259-284

Syed FS, Giorgi F, Pal JS, King MP (2006) Effect of remote forcings on the winter precipitation of central southwest Asia part 1: observations. Theor Appl Climatol 86:147-160

Syed FS, Giorgi F, Pal JS, Keay K (2010) Regional climate model simulation of winter climate over Central-Southwest Asia, with emphasis on NAO and ENSO effects. Int J Climatol 30:220-235
Takaya K, Nakamura H (2005) Mechanisms of intraseasonal amplification of the cold Siberian high. J Atmos Sci 62:4423-4440

Thompson DWJ, Wallace JM (1998) The Arctic Oscillation signature in the wintertime geopotential height and temperature fields. Geophys Res Lett 25:1297-1300

Torrance C, Compo GP (1998) A practical guide to wavelet analysis. B Am Meteorol Soc 79:61-78

Vallis GK, Gerber EP (2008) Local and hemispheric dynamics of the North Atlantic oscillation, annular patterns and the zonal index. Dyn Atmos Oceans 44:184-212

Wolter K, Timlin MS (2011) El Nino/Southern Oscillation behaviour since 1871 as diagnosed in an extended multivariate ENSO index (MEI.ext). Int J Climatol 31:1074-1087

Wu BY, Wang J (2002a) Possible impacts of winter Arctic Oscillation on Siberian high, the East Asian winter monsoon and sea-ice extent. Adv Atmos Sci 19:297-320

Wu BY, Wang J (2002b) Winter Arctic Oscillation, Siberian High and East Asian winter monsoon. Geophys Res Lett 29:1-4

Yadav RK, Rupa Kumar K, Rajeevan M (2009) Increasing influence of ENSO and decreasing influence of AO/NAO in the recent decades over northwest India winter precipitation. J Geophys ResAtmos 114:1-12

Yadav RK, Yoo JH, Kucharski F, Abid MA (2010) Why is ENSO influencing northwest India winter precipitation in recent decades? J Clim 23:1979-1993

Yatagai A, Arakawa O, Kamiguchi K, Kawamoto H, Nodzu MI, Hamada A (2009) A 44-year daily gridded precipitation dataset for Asia based on a dense network of rain gauges. SOLA 5:137-140

Zhu XH, Bothe O, Fraedrich K (2011) Summer atmospheric bridging between Europe and East Asia: influences on drought and wetness on the Tibetan Plateau. Quat Int 236:151-157 